\title{
What are the emotional experiences of being a volunteer in palliative and end-of-life care settings? A systematic review and thematic synthesis.
}

\begin{abstract}
Context: Previous research has focused on the risks of stress, burnout and the impact on general emotional well-being in paid palliative care staff, however volunteers in patientfacing roles are exposed to similar stressors. Volunteers increasingly provide emotional support to patients and families but receive little formal support for themselves. It is important to understand volunteers' emotional experiences of their role to identify strategies that could be implemented to support them effectively.
\end{abstract}

Objectives: To synthesise qualitative data on the emotional experiences of being a volunteer in palliative and end-of-life care settings, including how people cope with this role and how they can be best supported.

Methods: A systematic review with thematic synthesis design, with an iterative three-stage synthesis, including line-by-line coding, organising this into descriptive themes and then developing analytical themes. Four databases (PsycInfo, CINAHL, MEDLINE and EMBASE) were searched in November 2019. The Critical Appraisal Skills Programme was used to evaluate included papers.

Results: From the 22 included studies, four themes were developed: (1) intrinsic challenges (e.g. conflicting feelings); (2) extrinsic challenges (e.g. resources and expectations); (3) personal gain (e.g. learning and self-growth); and (4) developing relationships (e.g. appropriate boundaries). Challenges included personal feelings related to their role for example uncertainty, not being 'good enough' and feeling drained as well as frustrations within the palliative care system. 
Conclusion: Volunteers face unique challenges but also positive impacts that can affect their emotional well-being. It is important to monitor how volunteers are coping and provide appropriate support.

Keywords: qualitative research, hospices, hospice care, terminal care, palliative care, volunteers

\section{Key Message}

This systematic review and thematic synthesis provides an insight into the positive and negative emotional experience of palliative care volunteers in relation to their role. It highlights the unique intrinsic and extrinsic challenges faced. The results indicate a need to monitor how volunteers are managing and provide appropriate support. 


\section{Introduction}

Provision of high-quality palliative care requires a multi-disciplinary team approach, with such teams often including high numbers of volunteers, perhaps as many as 1.5 volunteers per paid member of $\operatorname{staff}(1)(2)$. There are approximately 500,000 hospice and palliative care volunteers in the United States and over 125,000 throughout the United Kingdom (UK)(3). First used primarily in 'back-office' roles such as administration, fundraising, and shops, they are increasingly found providing patient-facing care and support, with a recent survey showing that nearly $59 \%$ of services had patient-facing volunteers in a variety of settings including hospices, hospitals and the community(1)(4). Volunteers in such patient facing roles are integral in supporting patients at the end of life as they offer a different and complementary service to that of paid staff. For example, they are able to spend more time with patients, focusing on psychosocial needs. They are estimated to reduce hospice costs, in the UK by $23 \%$, indicating a financial benefit for hospices to recruit and retain volunteers(5). For effective retainment of volunteers, especially those in patient-facing roles, and to promote a positive volunteering environment, emotional well-being needs to be considered to ensure they are content and have effective resources to manage within their role.

People volunteer for a number of reasons including personal gain, altruism, civic responsibility and leisure(6). The volunteer role has developed over the years with more volunteers in patient-facing roles leading to an increasing interest across hospice and palliative care in developing these roles further(7). Volunteers are increasingly providing emotional care to patients and families, with $86 \%$ of UK hospices reporting that volunteers provide emotional care in inpatient settings(1). Volunteers providing emotional care is also common within community settings, with $68 \%$ of hospices surveyed reporting that volunteers are involved in counselling(1). Irrespective of whether individuals were volunteering their 
professional skills, counselling can be an emotionally demanding role and, without appropriate support and supervision, could negatively impact volunteers. Volunteers may also be with patients and families at the end of life, supporting them in a challenging time.

The emotional impact of working in palliative care settings for paid staff includes risk of burnout, stress and an impact on general emotional wellbeing(8). Although volunteers are exposed to similar stressors within palliative care, research is less likely to have focused on volunteers' emotional responses or considerations of support that could be implemented to assist in coping with their role. Recent literature reviews have focused on the contribution of volunteers' services to end-of-life care(7), personality traits(9), stressors(10), understanding the role of volunteers and exploring the distinction between paid staff and volunteers(11), the benefit of volunteers on patients and their families(12) and examining volunteers' experiences of being in inpatient hospital settings(13). However, there have been no literature reviews focusing exclusively on the emotional experience of being a palliative care volunteer.

\section{Methods}

\section{Aims}

This review aims to synthesise qualitative data on palliative care volunteers' emotional experiences of their role and how they manage this. The literature review question is "What are the emotional experiences of hospice volunteers in relation to their role and how do they manage this?"

\section{Design}

A systematic review with thematic synthesis design (14) was selected. This approach emulates thematic analysis within empirical research and includes both the author's and 
participants' interpretations of a particular experience. Thematic synthesis is an iterative three-stage synthesis including line-by-line coding, organising this into descriptive themes and then developing analytical themes. The researcher adopted a critical realist position, ontologically realist and epistemologically relativist(15). This indicates that the data obtained does not lead to direct access of reality, but that individuals' perceptions and beliefs affect their understanding of reality(14). This review is reported using the ENTREQ guidelines(16)

\section{Inclusion and exclusion criteria}

Inclusion and exclusion criteria are reported in Table 1 and focused on research on volunteers in palliative care settings with data on their emotional experiences.

\section{Data sources}

"MEDLINE”, "EMBASE", “CINAHL” and "PsycINFO" electronic databases were chosen as the most appropriate for this topic, and searched in November 2019. There were no date restrictions. A hand-search of references from the selected studies was also conducted.

\section{Search strategy}

A psychology subject librarian was consulted and agreed to the final search strategy. The research tool SPIDER (Sample, Phenomenon of Interest, Design, Evaluation, Research type)(17) was used to identify key parts of the research question and assisted in structuring the search strategy. The overall search concepts and how they were determined are presented in table 2.

Full-text search and database subject terms can be seen in supplementary table 1. Papers were exported onto a bibliography manager, Endnote (Version X9), and de-duplicated. The titles 
and abstracts of the remaining papers were read (author HC) and, if unsure of the suitability of a paper, the full text was read. Author CW acted as second checker, and appraised a quarter of the papers against the inclusion criteria to confirm inclusion, with disagreements being revolved via discussion.

\section{Critical appraisal}

The Critical Appraisal Skills Programme (CASP)(18) was selected to assess strengths and limitations of the included studies. CASP covers ten quality areas and the initial two questions identify papers which are unsuitable. The remaining questions cover design, sampling, data collection, the relationship between the participant and researcher, ethical issues, data analysis, findings and value of the research which generates an overall score. The rating system was a three-point system with strong evidence being given three points; moderate evidence being given two points; and weak evidence being given one point. The scores ranged from 12 to 22 (see supplementary table 2). Ratings were made by HC, with one quarter of the papers evaluated by $\mathrm{CW}$ to assess congruence with the appraisal of included papers. The ratings of papers corresponded between reviewers which enabled a final rating to be agreed. Papers were not excluded based on their reported quality as this could exclude relevant papers based on the reporting of the research rather than the research itself, but an understanding of their quality used in the synthesis and its focus(19).

\section{Data extraction}

Data were extracted by $\mathrm{HC}$, checked by $\mathrm{CW}$ and inputted into a summary table which included author, year, country, research question/aim, sample, design, data collection method(s) and findings. Where a study had data from volunteers and paid staff, only data related to volunteers was extracted. NVivo was used to manage data extraction and analysis. 


\section{Data analysis}

The process of deriving themes was inductive. HC coded and analysed papers and agreed on the findings with $\mathrm{CW}$. It was not a requirement of the chosen design for both researchers to independently code and analyse the data(14).

\section{Stage one}

Line-by-line coding of participants' accounts and authors' interpretations were developed through NVivo. As new studies were introduced, new codes were developed. Each sentence had at least one code although numerous codes could be used for a sentence. Initial codes were discussed with the team.

\section{Stage two}

Codes that appeared to be related were grouped together into more descriptive themes by the team. The original papers were consulted throughout to promote a close alignment with the experiences of participants in the original studies. A more hierarchical structure was introduced to coding, and similarities and differences were considered. A tree structure was developed to organise the themes.

\section{Stage three}

This stage involved making links between the descriptive themes from stage two to develop more analytical themes that encompassed hospice volunteers' emotional experiences of their role. This stage moved away from the original findings of the primary studies to develop more understanding and answer the review question.

\section{Results}


Twenty-two papers were included in the final synthesis (Figure 1)

Included studies (see table 3 for details) were conducted across a number of countries: South Africa $(n=1)$, Sweden $(n=1)$, United Kingdom $(n=7)$, Australia $(n=1)$, United States $(n=5)$, Canada $(\mathrm{n}=5)$, Switzerland $(\mathrm{n}=1)$ and Norway $(\mathrm{n}=1)$. All were published between 2002 and 2018, sample sizes ranged from 4 to 55 and participants were aged between 19 and 86 . Studies took place in a variety of settings.

\section{Derivation of themes}

Four themes were developed: intrinsic challenges, extrinsic challenges, personal gain and developing relationships. Supplementary table 3 shows the papers relevant to each theme. Table 4 shows how each theme draws from data within included papers, but this does not indicate the strength or importance of themes.

\section{Theme one: Intrinsic challenges}

This theme represents challenges that are related to the individual volunteer and how they felt within their role rather than the wider system of the hospice or challenges perceived to be caused by others. The impact of having conflicting feelings, uncertainty in the role, feelings of not being 'good enough' and feeling drained due to exposure to death will be discussed.

Participants across the studies discussed conflicting feelings in their role for example what they should be doing for patients based on their knowledge and training and how this could differ to their instincts. One participant discussed conflicting feelings in relation to dispensing medication which is something that would usually be deemed outside of a volunteers' role, however they struggled with this due to seeing a patient in pain: 
"I'm not supposed to be dispensing medication....it was, for me, a very uncomfortable and difficult situation to be in, cause on the one hand, you don't want to watch a human being suffer. On the other hand, it was made very clear to me that, you know, “this is something you don't do!","(20) (p.461)

Participants described a sense of uncertainty within their role and feeling unprepared for what they faced. Although some people felt more general training would be useful to mitigate this uncertainty, others felt it was a role that an individual would settle into with time and that increased training would not necessarily make a difference to feelings of uncertainty:

"Two participants suggested that it was not possible to be 'prepared for' every eventuality - some things simply had to be experienced and confidence came with time: From my experience I don't think... any amount of training could've prepared you for what you needed to do"(21) (p.281)

Whilst a volunteer is settling into the role, they need to be able to manage some uncertainty, nevertheless it could still be useful to provide a supportive forum once volunteers have been exposed to the realities of the role:

"“'Well when I first started, not knowing what to expect was the stress. Not knowing what I was walking in to or how to deal with it, or what to say, was always stressful at the beginning." 'Four of the participants described their first experiences as “fearful.",'(22) (p.190) 
Volunteers could feel uncomfortable and unsure about what to say to patients and this could play on their minds:

"I think about knowing the right thing to say, wondering if I'm going to upset the person I'm talking to, or is this person going to like me?"(23) (p.253)

Volunteers worried about the quality of support they provided to patients and whether they were 'good enough' in their role despite training. This led to feelings of uncertainty and questioning themselves:

"Issues that tilted this balance were related to internal struggle and a sense of insecurity about the adequacy and sufficiency of their efforts, even with the receipt of formal manualized training at the commencement of the volunteer work”.(24) (p.291)

As part of volunteers' roles, they have to manage seeing patients near to the end of life and/or dying. Some described feelings of grief in response to the death of patients which is a huge part of their role. If a volunteer continuously struggled with this, it would greatly affect the emotional impact of their role:

"The grief experienced by hospice volunteers was occasionally over-whelming. One volunteer noted: It's a part of you gone. It hurt so bad, all you can do is cry...I felt like if you cry too, it's weak. You know, men don't cry. But as I begin in this program, it makes no difference who see me cry. Ifeel for that person when they leave, but...I did everything I could for him, and he know I was right there".(25) (p.89) 
Experiencing grief and exposure to people at the end of life caused some to feel drained by volunteering due to intrinsic challenges and developing strong relationships with patients:

"One participant said she often felt physically drained following a hospice visit and would cope by going home and taking a rest”.(26) (p.401)

"It is very draining. The downfall with one-on-one home situations is that you get too attached (Vincent). You do develop a very close deep relationship with the patient and then there is real grief when the patient passes away (Joe)”.(27) (p.347)

\section{Coping with intrinsic challenges}

Intrinsic challenges were discussed as an inherent part of the role and volunteers touched upon how they managed these experiences.

"Taking time off from volunteering was a strategy mentioned by three volunteers (14\%) (e.g., "I stopped for a couple of months because I felt I needed time to regroup.")".(28) (p.261)

Some felt that these challenges decreased over time, some would temporarily cease volunteering and others would use different coping styles such as praying. It is important that the palliative care setting supports the volunteer in their coping styles.

\section{Theme two: Extrinsic challenges}


This theme represents challenges faced by volunteers related to external factors such as resources, what the volunteers see and frustrations within palliative care settings. Many participants described situations that had made them feel uncomfortable, for example patients and families having differing expectations of the volunteer role:

"Other care team members struggled with discordance between their understanding of their purpose and the care recipient or family member's perceptions of the volunteer's motives"..(24) (p.289)

Others commented on frustrations with the way the palliative care setting was run, for example not having enough information about patients and a delay in receiving referrals:

“We used to know more about the patients, but it was intruding on their privacy...it's a question of need-to-know, and we don't always know what we need to know"(29) (p.381)

"I got a referral recently and she died the next day"'(30) (p.527)

Some volunteers discussed feeling uncomfortable and helpless when family members had conversations in front of patients that could be distressing for the patients:

“...they were fighting, and I could hear them fine, so I knew she (the patient) could hear them fine and that was, that was very upsetting for me. I was sick to my stomach because I had to do something, I mean I was just sitting there, and I was kind of helpless".(22) (p.190) 
Others spoke more about feelings of frustration or disappointment at being pushed away by patients:

"I went in there and she started to speak then she just shut her eyes and wouldn't communicate... ...so you walk out thinking 'well I wish I'd known what to do'”. (21) (p.281)

Participants in the studies discussed feeling shocked when they saw some patients and how this could negatively affect them as a volunteer. Some felt that they had not been prepared enough by the hospice for what they might see in their role and others identified preparation in this area as very important, indicating the need for more training in this area:

"When I went to visit her there, not having seen her for some time I was ever so shocked at how she looked. She was unconscious, but her husband was there and I had to pretend that this wasn't bothering me too much. When I came out, I was absolutely shaking from head to foot".(31) (p.60)

Other extrinsic challenges discussed by participants were seeing patients suffering. This seemed to really affect some participants and strong emotive language was used to communicate this:

"I am traumatised having seen how my patients suffer"(32) (p.6) 
"Volunteers in 2 programs said that the thing they liked least about their volunteer work is seeing patients suffering (e.g., "The suffering .. . some of these people suffer something terrible...you wonder where these people get the strength'”)'. (30)(p.527)

\section{Coping with extrinsic challenges}

Participants discussed how they managed extrinsic challenges related to their role. There appeared to be a variety of coping mechanisms including talking with volunteer coordinators and other volunteers, leaving the challenging situation, religion and taking time off from volunteering:

"That is my main coping skill is to talk with out with [sic] my volunteer coordinator". (26) (p.399)

"Two volunteers said that they prayed or studied the bible to prevent burnout." (28)(p.261)

Although they identified a number of challenges and stressors within their roles and could discuss how they had managed this, volunteers did not seem to want to categorise these as negative experiences:

"Their voluntary work could be difficult at times, as they faced several tough situations, such as seeing a person suffer or watching a young person die. It was painful to experience the reactions that the terminally ill persons and/or their 
relatives could exhibit at the end of life. However, none of the volunteers characterized such experiences as negative"(33) (p.5)

It is unclear from the data provided why some volunteers did not categorise some of their experiences as negative. It may be that they also experienced a number of positive aspects to volunteering which could have overshadowed the negative aspects of the experience.

\section{Theme three: Personal gain}

This theme focuses on the positive outcomes of volunteering and what this adds to participants' lives. Most participants discussed what they had gained from their role for example feeling useful and appreciated by patients, feeling inspired and rewarded, giving back to others, learning from patients and self-growth. These gains seemed to be motivating factors for continuing to volunteer as well as making the challenges more manageable. Feeling useful to and appreciated by patients and families seemed to be very important to participants across the studies and was evidenced through receiving positive feedback, the reactions of patients and patients sharing personal information with them:

“...they felt joy and satisfaction after performing their duties well and receiving positive responses from patients, relatives and personnel".(34) (p.605)

"Volunteers articulated to others the value of their physical presence with patients by underscoring the immediate and discernible results of their service as evidenced by "see[ing] the look on their [patients'] faces or see[ing] them smile." Thus, selfsatisfaction was indelibly linked to their ability to discern impact and appreciation in real-time”.(35) (p.575) 
Many spoke of finding their role rewarding thus making their role a positive experience and bringing them satisfaction:

"The biggest reward is in the heart...we get as much, or more, out of helping them as they get from us ..” (36) (p.1534)

“The volunteers...expressed personal satisfaction and reported that volunteering with the service had given them a sense of purpose and had been very rewarding”.(37) (p.1423)

As participants felt appreciated, useful and rewarded, it makes sense that this brought enjoyment to their time volunteering in palliative care:

"Some participants mentioned psychological gains, such as feeling good about helping others in need or from gaining a different perspective on their own life: 'I know it sounds very prudish, but I do enjoy helping people who need help ', (29) (p.379)

"They took great satisfaction from their work and described it as challenging, rewarding, and useful. These results are consistent with the literature on volunteering in hospice and palliative care”.(38) (p.605)

They also spoke about learning from patients and how this could also help to build relationships: 
"I think she sees me as a friend, also someone to maybe pass on some of her wisdom, because she has these little pearls she drops occasionally”.(23) (p.250)

"Five volunteers noted how much they had learned from patients' life experiences"(39) (p.485)

Overall, it seemed that participants experienced self-growth and general personal development through their role as a volunteer:

"Many of the volunteers indicated that volunteering enabled them to achieve selfgrowth and personal emotional and psychological development”.'(32) (p.5)

"At every encounter, I have the feeling of gaining insight into human universes, always fascinating and never the same”.(38) (p.603)

Some spoke of gaining more perspective on their own lives and becoming more grateful for what they had:

"One participant explained that she would often think about how lucky she was when she found herself in a stressful situation”.(26) (p.400)

Others felt their role had enabled them to become stronger in themselves and cope with more, indicating that they would get better and more comfortable with their role over time: 
"Emotional resilience was the product of direct personal experience of pain and loss, as well as exposure to death and dying in the volunteer settings".(40) (p.19)

Many discussed how they had been changed as a person through volunteering:

"Nearly all of the volunteers acknowledged that they were different now or had changed in some way as a result of their volunteer experience”. (28)(p.262)

Being changed could be linked to the challenges faced by volunteers but also the personal gains and self-development that comes with the role such as feeling useful, learning from patients and feeling inspired.

\section{Theme four: Developing relationships}

Relationships with patients and families were important to participants across the studies and this was discussed in relation to forming close relationships, having appropriate boundaries, understanding the patient's experience and having curiosity and flexibility when working with patients. Although volunteers were not directly involved in patients' medical care, they offered holistic care through spending time with patients, which can support deep connection:

"Volunteers come to care deeply about patients and want what is best for them without being able to openly make suggestions".(20) (p.460)

This could be challenging if volunteers felt as though they had good ideas for things that could enhance a patient's well-being. It seemed that closer relationships would form if the patient and volunteer were alike or held similar values: 
"We instantly connected because we left out all the bullshit and just connected on a human level...We connect as two women...So, she, I realized, shares the dreams and desires and aspirations that I have. We're sisters under the skin"(23) (p.250)

Some held clarity about their role in the volunteer-patient relationship and were aware that this would soon end as they were working in palliative care and the patient would die:

"There was certainly an agreement that volunteers valued the closeness with dying patients and cherished the experience. This closeness appeared less like an emotional attachment and more like accompanying another on a journey at the end of which parting was inevitable. Volunteers understood that they had to "let go" and that the investment was a unique one. This delicate balance of connections and distance was well understood...they acknowledged that the ability to maintain this balance was an essential quality in a volunteer"(40) (p.22)

This enabled the volunteers to protect themselves emotionally from an overwhelming sense of grief when their patient died. However, other volunteers took a different position and felt the connections made would inevitably lead to grief:

"You do develop a very close deep relationship with the patient and then there is real grief when the patient passes away”. (27)(p.347) 
Although it seems that volunteers had differing views on their role within the patient's life and the level to which they should become emotionally involved, another participant described their views as somewhere in the middle:

"I'm happy and I'm sad. Because I know that the patient, from my belief system, that the patient is on to a better life, a better existence. And it's sad, because the human part of me and the connection that we've made, to see that person go”. (25)(p.88)

Due to strong relationships forming, some questioned whether they had become too attached to their patients and that others had also commented on this:

"Karen consequently questioned whether she had become too attached to the patients and their families: "I suppose you do get attached even though you try not to. I know my husband worries about it. He worries about me getting too involved.",'(37) (p.1422)

Sometimes this awareness could lead to the development of stronger boundaries with patients, whether that meant being somewhat emotionally removed or spending less time with them. This is important as the role of a volunteer is not always clear to patients with regards to expectations of what they 'should' give:

"Issues might be as simple as being asked to stay for longer hours as one might ask of a friend but not of a professional"(20) (p.461) 
Some participants deliberately put up internal barriers as a way of managing the emotional burden of losing a patient:

"I don't allow her to climb completely into my heart, and I don't climb completely into hers. There's a certain boundary that I reserve for my own sanity, because I know that she will die eventually"(23). (p.254)

Close relationships that form between volunteers and patients, can spark a curiosity within volunteers about the patients' health conditions but they do not necessarily need this information:

"All the time those questions are there...I wonder what is wrong with him or her. It may be someone you see a lot, others you never see. I haven't felt OK to ask either, since somehow we have got to know that we don't need to know what's up with people,’.(34) (p.605)

A friend or professional would often know what is wrong with someone, however volunteers appear to be in a limbo and do not receive much information which can be challenging. This could be a barrier in developing a close relationship and also requires an understanding that patients will share this information if they wish. Boundaries are important to consider due to maintaining the role of 'volunteer' rather than 'friend'.

\section{Discussion}

This review focused on the emotional experiences of being a palliative care volunteer. A number of intrinsic challenges such as how the volunteer felt within their role including 
feelings of uncertainty, not being 'good enough' and feeling drained were identified.

Extrinsic challenges were also recognised, including challenges related to external factors such as resources, what the volunteer sees within their role and frustrations with the setting. More positive emotional experiences were highlighted such as the process of developing relationships with patients and families and the personal gains of volunteering. Personal gains include what volunteering adds to the volunteers' lives, positive feelings initiated by the role (for example, feelings useful, appreciated and inspired) and general self-growth. It is clear that the role of a volunteer is different to that of paid staff. Although challenges faced by volunteers sometimes overlap with paid staff, they have unique traits that need to be considered.

The intrinsic and extrinsic challenges related to volunteers' roles impacted on their emotional experience of the role. Other reviews have also identified challenges; stressors can include limited emotional support (extrinsic), the need for more training (extrinsic), dealing with the patient's family (extrinsic), dealing with death and dying (intrinsic) and not being able to do more for patients linking to an intrinsic challenge of not feeling 'good enough'(7). These challenges are not unique to palliative care, with similar emotional burdens identified with volunteers working with those with dementia(41). This resonates with the findings of this review with regards to the development of good relationships with the implementation of boundaries to protect both the patient's expectations and the volunteer. Other challenges included not feeling 'good enough' or that they were not doing enough for their patient. Similar challenges are highlighted in the befriending literature where volunteers felt a sense of guilt or anxiety that they were not doing enough(44). 
Coping with intrinsic and extrinsic challenges within the volunteers' role was central. Coping is an individual's attempt to manage or reduce external and internal demands(42). The volunteers had a number of coping strategies to draw upon including talking with volunteer coordinators, leaving the situation they found challenging, religion and taking time away from volunteering. These findings are supported in other reviews which present coping strategies as either problem-focused, emotion-focused or meaning-making through appraisal(7). The development of coping strategies through the palliative care volunteer role can impact the volunteer's wider life as they have experienced personal growth through managing their experiences.

Increased training for palliative care volunteers has been widely discussed (43)(7). This supports the findings in the current review which indicates that more training on ethical issues, death and preparing for patients dying and managing disfigurement could be useful. Other reviews have indicated the importance of organisational support in helping people to manage challenges from their workplace(44). Volunteers require a good level of self-care to manage their role(45) therefore training could be implemented to support volunteers to develop and maintain self-care strategies. Previous research indicates that it is rare for palliative care volunteers to experience burnout or compassion fatigue related to their role, in comparison to paid staff(46). However, there has been little research on compassion satisfaction which is defined as the fulfilment individuals feel when caring for others(47) and is a factor that could offset the risks of burnout(48).

The positive aspects of palliative care volunteers' role can outweigh the negative: overall the role contributes positively to emotional well-being. Resilience in palliative healthcare professionals has been suggested to help them overcome difficulties(49) whilst others 
indicate it is more about adapting to these challenging situations(50). Volunteers, similarly to paid staff, manage exposure to death and dying and ethical issues regularly within their role, therefore resilience is a key factor that can help volunteers to manage their experiences(51). It is important that volunteers are given the time and space to reflect on their experiences to reduce the likelihood of them coping through emotional detachment and help them to foster resilience. This less adaptive way of coping has been shown in palliative care nurses who did not have time to reflect on their experiences(52). Other strategies that have been useful for some informal caregivers in promoting resilience and effective coping include: developing active coping skills, focusing on positive aspects of caring for others and encouraging the development of personal meaning from their experiences(53). These findings could be useful to consider when setting up further support for volunteers.

Positive aspects of volunteering were also reflected in the wider literature. Personal gain can be viewed as a motivation for continuing to volunteer as this indicates that the volunteers also benefit from giving time to patients and feel connected to those that they are supporting. A number of different motivations have been highlighted throughout the literature and appear to be similar across countries and settings(7). For example, research into volunteering in mental health settings show that volunteers experience personal gain from their role (feeling useful, learning from patients and self-growth)(54). This is also indicative of feelings of competence within their role. Similarly, peer support volunteers for people with limb loss also experienced positive benefits of volunteering such as feeling a sense of pride, purpose and usefulness(55). These positive aspects of volunteering can be seen as representative of intrinsic motivation from the self-determination theory (SDT) where the individual is inherently interested in their role and enjoys it; competence and relatedness have been highlighted above and volunteers also have a sense of autonomy as they are choosing to 
engage in their role and have freedom over their behaviour(56). These findings also contribute to the indication that volunteers experience compassion satisfaction(47). This level of personal satisfaction can contribute to reduced stress in the workplace, being a protective factor against stress and burnout(57).

A key finding from this review was the importance for volunteers of developing a good relationship with patients. Building close relationships, considering boundaries and understanding the patient experience with flexibility and curiosity has also been found in other reviews. The social nature of the role has previously been discussed with the role being characterised in social terms rather than the tasks they do and this has been found across different palliative care settings(11). This is also supported within the befriending literature where a core element of volunteers as befrienders for those with cancer, depression and other mental health difficulties was developing social relationships(58). Other research supports the findings of strong relationships forming between the volunteer and patient, also classed as a personal gain(54). It has been identified that volunteers struggle if a strong connection has not been made with a patient which highlights the importance of this development(59).

The befriending literature separates types of befriending into a 'friendship' style befriending and a 'professional' style of befriending which raises different questions regarding boundaries(60). Volunteers in the current review appeared to choose where they naturally fell on that continuum and, whilst close relationships developed between volunteers and patients, some volunteers highlighted situations where boundaries needed to be implemented. How a volunteer implemented boundaries was personal to the volunteer but it was recognised that a lack of boundaries could result in a bigger emotional impact when the patient died. This 
indicates that there are higher emotional risks of 'true friendship' in comparison to a 'professional' befriending relationship which supports the current findings (60).

The findings of the current review support the job-demands resources (JD-R) model(61) as psychological processes influence the development of job strain and motivation. However, this model does not specify how demands and resources interact. (SDT)(62) indicates that demands lead to burnout if the individual has low resources. This highlights the importance of individuals developing a range of resources to support them. It describes autonomous motivation, including intrinsic and extrinsic motivations and controlled motivation(63). Autonomous motivation describes feelings of choice, interest and value, either doing something because it is interesting (intrinsic motivation) or because it leads to a consequence (extrinsic motivation)(64). The current review highlights personal gain in the selected papers which encompasses both intrinsic and extrinsic motivation as the papers described volunteers feeling useful, appreciated, inspired and rewarded (intrinsic) but also provided them with learning from patients and self-growth (extrinsic). Controlled motivation, where an individual does something in order to get a reward or avoid punishment(65), was not highlighted in the current review. This is positive as individuals are usually more engaged and have greater levels of emotional well-being when they are autonomously motivated(66).

The SDT also encompasses the three basic human psychological needs from the cognitive evaluation theory: competence, relatedness and autonomy(67). The current review highlights these basic needs. For example, some of the intrinsic challenges highlighted were not always feeling 'good enough'. This is linked to the basic need of competence hence why volunteers may find it challenging to feel this way. Relatedness is also present through the development of relationships between volunteers, patients and families. This gives them the chance to both 
care for others and have others care about and value them. It seems that this psychological need is largely met in the current review, but it can be challenging when patients push volunteers away and this may be because it contradicts the volunteers' need for relatedness. Autonomy was not explicitly highlighted in the current review; however, volunteers had some level of choice and control over their coping strategies used to manage challenges within palliative care. They also had autonomy over whether or not they continued to volunteer as they were not financially tied to their role.

Overall, the evidence highlights the benefit of focusing on support, coping and training for volunteers but does not suggest a particular focus on characteristics or traits in volunteers that should be used in the recruitment and selection processes.

\section{Strengths and limitations}

This systematic review and thematic synthesis is the first to directly examine the emotional experiences of being a palliative care volunteer and provides evidence that volunteers face specific challenges within their role and could benefit from more structured support. The search was comprehensive and used a range of databases to obtain papers. No date or study design restrictions were implemented in an attempt to capture all relevant research that was published in English. Research in other languages was excluded due to limited time and money for translation and interpretation, therefore some relevant papers in other languages could have been missed. Papers were critically appraised; however, none were excluded based on this score. This is due to a limited number of papers that met the inclusion criteria and it being a contested area in qualitative synthesis(68).

\section{Recommendations for future research, practice and policy}


The impact of volunteers' roles on their emotional well-being, was not a focus of most included papers. It would be useful for research to consider the specific impacts of the role on volunteers' emotional well-being and explore what volunteers would find useful to support them. Initially, it would be helpful to gather qualitative data to explore volunteers' experiences and subsequently develop quantitative research from this to gather a wider range of data. It is important that when reporting research, authors focus on outlining clear and detailed methodology as this was missing from some papers included in the review thus impacting on their quality.

It is understood that volunteering in palliative care can present a number of challenges and that prolonged stress can negatively impact an individual both physically and psychologically(69). Therefore, it would be useful for palliative care services to consider the importance of stress-reducing techniques training for volunteers, such as imagery, mindfulness and breathing techniques(48). A focus on stress reduction, particularly through practicing mindfulness, has been shown to increase health outcomes for both clinical and nonclinical populations(70). The importance of enhancing psychological well-being for healthcare professionals working in palliative care has previously been indicated(71), therefore it would be useful for this to translate to the volunteers.

Volunteers may also benefit from a space to reflect on their sense of self and general emotional well-being in relation to their role. Extrinsic challenges may also be addressed in a reflective space and it could be useful to focus these discussions on how volunteers make sense of extrinsic challenges. Clinical supervision groups can reduce the risk of burnout in palliative care professionals(72), reduce anxiety, increase confidence and commitment to the role(73). Some extrinsic challenges could be considered on a more organisational level, some 
of which could be addressed through additional training. This may include knowing what to say to patients and preparation for seeing suffering and physical disfigurements. Both formal and informal support can promote coping and resilience in palliative care nurses(44), thus would be useful to consider for volunteers.

To gain more understanding of people who struggle with the role, it may be useful to conduct research on previous volunteers who no longer felt able to continue in their role. This could give more insight into the stressors they encountered and support considerations of what the palliative care setting could have done to support them.

\section{Conclusion}

Palliative care volunteers are less likely to experience stress and burnout than paid staff. However, this does not mean that the emotional impact of their role should not be considered. Understanding volunteers' experiences has previously been emphasised as important as this can assist settings in recognising suitable support which can influence overall well-being(41) (74). Volunteers face unique challenges which can impact on their emotional well-being but also experience a number of positive impacts on their emotional well-being. It is important to monitor how volunteers are coping with their role and provide support where appropriate.

\section{Conflict of interest statement}

Nothing to disclose.

\section{Funding statement}

This research did not receive any specific grant from funding agencies in the public, commercial, or not-for-profit sectors. 


\section{References}

1. Burbeck R., Low J., Sampson E.L., Bravery R., Hill M., Morris S., et al. Volunteers in specialist palliative care: A survey of adult services in the United Kingdom. J Palliat Med. 2014;17(5):568-74.

2. Siouta N, Van Beek K, van der Eerden ME, Preston N, Hasselaar JG, Hughes S, et al. Integrated palliative care in Europe: a qualitative systematic literature review of empirically-tested models in cancer and chronic disease. BMC Palliat Care. $2016 \mathrm{Jul}$ 8;15(1):56.

3. Hospice facts and figures | Media centre | Hospice UK [Internet]. [cited 2020 Apr 12]. Available from: https://www.hospiceuk.org/about-hospice-care/media-centre/factsand-figures

4. The challenges of caring for people dying from COVID-19: a multinational, observational study (CovPall) - Journal of Pain and Symptom Management [Internet]. [cited 2021 Feb 12]. Available from: https://www.jpsmjournal.com/article/S08853924(21)00159-7/fulltext

5. Help the Hospices. Volunteer Value; A pilot survey in UK hospices. London: Help the Hospices. 2006.

6. Claxton-Oldfield S, Jefferies J, Fawcett C, Wasylkiw L, Claxton-Oldfield J. Palliative Care Volunteers: Why Do They Do It? J Palliat Care. 2004 Jun;20(2):78-84.

7. Morris S, Wilmot A, Hill M, Ockenden N, Payne S. A narrative literature review of the contribution of volunteers in end-of-life care services. Palliat Med. 2013 May;27(5):428-36.

8. Kamau C, Medisauskaite A, Lopes B. Orientations can avert psychosocial risks to palliative staff: Orientations. Psychooncology. 2014 Jun;23(6):716-8.

9. Starnes BJ, Wymer WW. Demographics, Personality Traits, Roles, Motivations, and Attrition Rates of Hospice Volunteers. J Nonprofit Public Sect Mark. 2000 Apr 27;7(2):61-76. 
10. Claxton-Oldfield S. Hospice palliative care volunteers: A review of commonly encountered stressors, how they cope with them, and implications for volunteer training/management. Am J Hosp Palliat Med. 2016 Mar;33(2):201-4.

11. Burbeck R, Candy B, Low J, Rees R. Understanding the role of the volunteer in specialist palliative care: a systematic review and thematic synthesis of qualitative studies. BMC Palliat Care. 2014 Feb;13(1):1-23.

12. Candy B., France R., Low J., Sampson L. Does involving volunteers in the provision of palliative care make a difference to patient and family wellbeing? A systematic review of quantitative and qualitative evidence. Int J Nurs Stud. 2015;52(3):756-68.

13. Bloomer MJ, Walshe C. 'It's not what they were expecting': A systematic review and narrative synthesis of the role and experience of the hospital palliative care volunteer. Palliat Med. 2020 Feb 17;026921631989902.

14. Thomas J, Harden A. Methods for the thematic synthesis of qualitative research in systematic reviews. BMC Med Res Methodol. 2008 Jul 10;8(1):45.

15. Bhaskar R. Critical realism and the ontology of persons. J Crit Realism. 2020 Mar $14 ; 19(2): 113-20$.

16. Tong A, Flemming K, McInnes E, Oliver S, Craig J. Enhancing transparency in reporting the synthesis of qualitative research: ENTREQ. BMC Med Res Methodol. $2012 \mathrm{Nov}$ 27;12(1):181.

17. Cooke A, Smith D, Booth A. Beyond PICO: The SPIDER Tool for Qualitative Evidence Synthesis. Qual Health Res. 2012 Oct 1;22(10):1435-43.

18. Critical Appraisal Skills Programme. CASP Qualitative Checklist. 2018; Available from: http://www.casp-uk.net/checklists

19. Malpass A, Shaw A, Sharp D, Walter F, Feder G, Ridd M, et al. "Medication career" or "Moral career"? The two sides of managing antidepressants: A meta-ethnography of patients' experience of antidepressants. Soc Sci Med. 2009 Jan 1;68(1):154-68.

20. Berry P, Planalp S. Ethical issues for hospice volunteers. Am J Hosp Palliat Med. 2009 Dec;25(6):458-62.

21. Dean A., Willis S. 'A strange kind of balance': Inpatient hospice volunteers' views on role preparation and training. Prog Palliat Care. 2017;25(6):279-85.

22. Brown MV. The stresses of hospice volunteer work. Am J Hosp Palliat Med. 2011 May;28(3):188-92.

23. Foster E. Lessons we learned: Stories of volunteer-patient communication in hospice. J Aging Identity. 2002 Dec;7(4):245-56. 
24. Azuero C.B., Harris G.M., Allen R.S., Williams B.R., Kvale E., Ritchie C.S. Team-based volunteerism with the seriously ill: a qualitative analysis from 10 volunteers' perspectives. J Soc Work End--Life Palliat Care. 2014;10(3):282-95.

25. Supiano KP, Cloyes KG, Berry PH. The grief experience of prison inmate hospice volunteer caregivers. J Soc Work End--Life Palliat Care. 2014 Jan;10(1):80-94.

26. Brown MV. How they cope: A qualitative study of the coping skills of hospice volunteers. Am J Hosp Palliat Med. 2011 Sep;28(6):398-402.

27. Weeks LE, MacQuarrie C. Supporting the volunteer career of male hospice-Palliative care volunteers. Am J Hosp Palliat Med. 2011 Aug;28(5):342-9.

28. Claxton-Oldfield S, Claxton-Oldfield J. The impact of volunteering in hospice palliative care. Am J Hosp Palliat Med. 2007 Aug;24(4):259-63.

29. Elliott G, Umeh K. Psychological issues in voluntary hospice care. Br J Nurs. $2013 \mathrm{Apr}$ 11;22(7):377-83.

30. Claxton-Oldfield S, Claxton-Oldfield J. Should I stay or should I go: A study of hospice palliative care volunteer satisfaction and retention. Am J Hosp Palliat Med. 2012 Nov;29(7):525-30.

31. Dein S, Abbas SQ. The stresses of volunteering in a hospice: A qualitative study. Palliat Med. 2005 Jan;19(1):58-64.

32. Akintola O. Perceptions of rewards among volunteer caregivers of people living with AIDS working in faith-based organizations in South Africa: A qualitative study. J Int AIDS Soc. 2010;13(1):22.

33. Soderhamn U., Flateland S., Fensli M., Skaar R. To be a trained and supported volunteer in palliative care - A phenomenological study. BMC Palliat Care. 2017;16(1):18.

34. Andersson B, Öhlén J. Being a hospice volunteer. Palliat Med. 2005 Dec;19(8):602-9.

35. White ZM, Gilstrap CM. 'People just don't understand': Challenges communicating home hospice volunteer role experiences to organizational outsiders. Manag Commun Q. 2017 Nov;31(4):559-83.

36. Claxton-Oldfield S, McCaffrey-Noviss W, Hicks R. A few good men: It's not easy recruiting male hospice palliative care volunteers. Am J Hosp Palliat Med. 2018 Dec;35(12):1532-9.

37. Beasley E., Brooker J., Warren N., Fletcher J., Boyle C., Ventura A., et al. The lived experience of volunteering in a palliative care biography service. Palliat Support Care. 2015;13(5):1417-25. 
38. Delaloye S., Escher M., Luthy C., Piguet V., Dayer P., Cedraschi C. Volunteers trained in palliative care at the hospital: an original and dynamic resource. Palliat Support Care. 2015;13(3):601-7.

39. Planalp S, Trost MR, Berry PH. Spiritual feasts: Meaningful conversations between hospice volunteers and patients. Am J Hosp Palliat Med. 2011 Nov;28(7):483-6.

40. Guirguis-Younger M, Grafanaki S. Narrative accounts of volunteers in palliative care settings. Am J Hosp Palliat Med. 2008 Feb;25(1):16-23.

41. Smith R, Drennan V, Mackenzie A, Greenwood N. Volunteer peer support and befriending for carers of people living with dementia: An exploration of volunteers' experiences. Health Soc Care Community. 2018;26(2):158-66.

42. Folkman S, Lazarus RS. An Analysis of Coping in a Middle-Aged Community Sample. J Health Soc Behav. 1980;21(3):219-39.

43. MacLeod A., Skinner M.W., Low E. Supporting hospice volunteers and caregivers through community-based participatory research. Health Soc Care Community. 2012;20(2):190-8.

44. Gillman L, Adams J, Kovac R, Kilcullen A, House A, Doyle C. Strategies to promote coping and resilience in oncology and palliative care nurses caring for adult patients with malignancy: a comprehensive systematic review. JBI Evid Synth. 2015 May;13(5):131-204.

45. Pesut B., Hooper B., Lehbauer S., Dalhuisen M. Promoting volunteer capacity in hospice palliative care: a narrative review. Am J Hosp Palliat Care. 2014;31(1):69-78.

46. Kavalieratos D, Siconolfi DE, Steinhauser KE, Bull J, Arnold RM, Swetz KM, et al. "It Is Like Heart Failure. It Is Chronic ... and It Will Kill You": A Qualitative Analysis of Burnout Among Hospice and Palliative Care Clinicians. J Pain Symptom Manage. 2017 May 1;53(5):901-910.e1.

47. Stamm BH. The concise ProQOL manual. 2010.

48. Hotchkiss JT. Mindful Self-Care and Secondary Traumatic Stress Mediate a Relationship Between Compassion Satisfaction and Burnout Risk Among Hospice Care Professionals. Am J Hosp Palliat Med. 2018 Aug;35(8):1099-108.

49. Connor KM, Davidson JRT. Development of a new resilience scale: The ConnorDavidson Resilience Scale (CD-RISC). Depress Anxiety. 2003;18(2):76-82.

50. Hornor G. Resilience. J Pediatr Health Care. 2017 May 1;31(3):384-90.

51. Zanatta F, Maffoni M, Giardini A. Resilience in palliative healthcare professionals: a systematic review. Support Care Cancer. 2020 Mar 1;28(3):971-8.

52. Powell MJ, Froggatt $K$, Giga S. Resilience in in patient palliative care nursing: a qualitative systematic review. BMJ Support Palliat Care. 2020 Mar;10(1):79-90. 
53. Palacio G C, Krikorian A, Gómez-Romero MJ, Limonero JT. Resilience in Caregivers: A Systematic Review. Am J Hosp Palliat Med. 2019 Dec 13;1049909119893977.

54. Cassidy M, Thompson R, El-Nagib R, Hickling LM, Priebe S. Motivations and experiences of volunteers and patients in mental health befriending: a thematic analysis. BMC Psychiatry. 2019 Apr 17;19(1):116.

55. Richardson L-J, Molyneaux V, Murray CD. Being a peer support mentor for individuals who have had a lower limb amputation: an interpretative phenomenological analysis. Disabil Rehabil. 2019 May 10;1-8.

56. Gagné M, Deci EL. Self-determination theory and work motivation. J Organ Behav. 2005;26(4):331-62.

57. Kamal AH, Bull JH, Wolf SP, Swetz KM, Shanafelt TD, Ast K, et al. Prevalence and Predictors of Burnout Among Hospice and Palliative Care Clinicians in the U.S. J Pain Symptom Manage. 2016 Apr;51(4):690-6.

58. Siette J, Cassidy M, Priebe S. Effectiveness of befriending interventions: a systematic review and meta-analysis. BMJ Open. 2017 Apr 1;7(4):e014304.

59. Greenwood DE, Gordon C, Pavlou C, Bolton JV. Paradoxical and powerful: Volunteers' experiences of befriending people with dementia. Dementia. 2018 Oct 1;17(7):821-39.

60. Thompson R, Valenti E, Siette J, Priebe S. To befriend or to be a friend: a systematic review of the meaning and practice of "befriending" in mental health care. J Ment Health. 2016 Jan 2;25(1):71-7.

61. Bakker AB, Demerouti E. The Job Demands-Resources model: state of the art. J Manag Psychol. 2007 Jan 1;22(3):309-28.

62. Deci EL. Ryan, RM. Intrinsic motivation and self-determination in human behavior. $\mathrm{N} Y$ Lond Plenum. 1985;86.

63. Deci EL, Ryan RM. The 'What' and 'Why' of Goal Pursuits: Human Needs and the SelfDetermination of Behavior. Psychol Inq. 2000;11(4):227-68.

64. Fernet $\mathrm{C}$, Austin S, Vallerand RJ. The effects of work motivation on employee exhaustion and commitment: An extension of the JD-R model. Work Stress. 2012 Jul 1;26(3):213-29.

65. Langan E, Hodge K, McGowan S, Carney S, Saunders V, Lonsdale C. The influence of controlled motivation alongside autonomous motivation: Maladaptive, buffering, or additive effects? Int J Sport Exerc Psychol. 2016 Jan 2;14(1):57-71.

66. Ntoumanis N. A self-determination theory perspective on motivation in sport and physical education: Current trends and possible future research directions. Motiv Sport Exerc. 2012;3(1):91-128. 
67. Adams N, Little TD, Ryan RM. Self-Determination Theory. In: Wehmeyer ML, Shogren KA, Little TD, Lopez SJ, editors. Development of Self-Determination Through the LifeCourse [Internet]. Dordrecht: Springer Netherlands; 2017 [cited 2020 Apr 12]. p. 4754. Available from: https://doi.org/10.1007/978-94-024-1042-6_4

68. Carroll C, Booth A. Quality assessment of qualitative evidence for systematic review and synthesis: Is it meaningful, and if so, how should it be performed? Res Synth Methods. 2015;6(2):149-54.

69. Salvagioni DAJ, Melanda FN, Mesas AE, González AD, Gabani FL, de Andrade SM. Physical, psychological and occupational consequences of job burnout: A systematic review of prospective studies. PLOS ONE. 2017;12(10).

70. Rush SE, Sharma M. Mindfulness-Based Stress Reduction as a Stress Management Intervention for Cancer Care: A Systematic Review. J Evid-Based Complement Altern Med. 2017 Apr 1;22(2):348-60.

71. Medland J, Howard-Ruben J, Whitaker E. Fostering Psychosocial Wellness in Oncology Nurses: Addressing Burnout and Social Support in the Workplace. Oncol Nurs Forum. 2004 Jan 1;31(1):47-54.

72. Chilvers R, Ramsey S. Implementing a clinical supervision programme for nurses in a hospice setting. Int J Palliat Nurs. 2009 Dec 1;15(12):615-9.

73. O'Donovan A, Halford WK, Walters B. Towards Best Practice Supervision of Clinical Psychology Trainees. Aust Psychol. 2011;46(2):101-12.

74. Stockwell-Smith G, Jones C, Moyle W. 'You've got to keep account of heads all the time': staff perceptions of caring for people with dementia. J Res Nurs. 2011 Sep 1;16(5):400-12. 